\title{
ON THE RATIO BETWEEN SUCCESSIVE RADII OF A SYMMETRIC CONVEX BODY
}

\section{BERnARDo GONZÁlEZ MERINO}

Abstract. In this note we study the upper bound for the ratio between the so called successive inner and outer radii of a 0 -symmetric convex body $K$. This problem was studied by Perel'man and Pukhov and it is a natural generalization of the classical results of Jung and Steinhagen.

Mathematics subject classification (2010): Primary 52A20; Secondary 52A40.

Keywords and phrases: Inner and outer radii, Perel'man-Pukhov problem.

\section{REFERENCES}

[1] U. BetKe, M. HenK, Estimating sizes of a convex body by successive diameters and widths, Mathematika 39, 2 (1992), 247-257.

[2] U. Betke, M. Henk, A generalization of Steinhagen's theorem, Abh. Math. Sem. Univ. Hamburg 63 (1993), 165-176.

[3] T. Bonnesen and W. Fenchel, Theorie der konvexen Körper, Springer, Berlin, 1934, 1974. English translation: Theory of convex bodies. Edited by L. Boron, C. Christenson and B. Smith. BCS Associates, Moscow, ID, 1987.

[4] R. BRAndenberg, Radii of regular polytopes, Discrete Comput. Geom. 33, 1 (2005), 43-55.

[5] R. BRAndenberg, T. Theobald, Radii minimal projections of polytopes and constrained optimization of symmetric polynomials, Adv. Geom. 6, 1 (2006), 71-83.

[6] P. Gritzmann, V. KleE, Inner and outer $j$-radii of convex bodies in finite-dimensional normed spaces, Discrete Comput. Geom. 7 (1992), 255-280.

[7] M. HenK, A generalization of Jung's theorem, Geom. Dedicata 42 (1992), 235-240.

[8] M. Henk, M. A. Hernández Cifre, Intrinsic volumes and successive radii, J. Math. Anal. Appl. 343, 2 (2008), 733-742.

[9] M. Henk, M. A. Hernández Cifre, Successive minima and radii, Canad. Math. Bull. 52, 3 (2009), 380-387.

[10] G. Ya. Perel'man, On the k-radii of a convex body, (Russian) Sibirsk. Mat. Zh. 28, 4 (1987), 185-186. English translation: Siberian Math. J. 28, 4 (1987), 665-666.

[11] S. V. Pukhov, Inequalities for the Kolmogorov and Bernštern widths in Hilbert space, (Russian) Mat. Zametki 25, 4 (1979), 619-628, 637. English translation: Math. Notes 25, 4 (1979), 320-326. 